УДК 37:004.891.3

Колгатін Олександр Геннадійович, доктор педагогічних наук, професор кафедри інформатики Харківського національного педагогічного університету імені Г. С. Сковороди, м. Харків, e-mail: kolgatin@ yahoo.com

\title{
ЧАС ВИКОНАННЯ ЯК ОДИН ІЗ ПОКАЗНИКІВ ЯКОСТІ ТЕСТОВИХ
}

ЗАВДАНЬ

\section{Анотація}

Проблема впливу характеристик тестових завдань на точність результатів педагогічного тестування досліджується за допомогою розробленої автором методики проведення обчислювальних експериментів, яка грунтується на методі статистичних випробувань і моделі Г. Раша. Запропоновано критерій якості результатів тестування як різницю ймовірностей правильного та помилкового ранжування тестованих. За результатами обчислювальних експериментів досліджено залежність цього критерію від параметра роздільної здатності й кількості завдань тесту. Запропоновано емпіричну функцію для апроксимації отриманих даних, аналіз якої дав змогу рекомендувати критерій якості завдання, що враховує показники часу виконання й роздільної здатності.

Ключові слова: тест, час, роздільна здатність, обчислювальний експеримент, точність.

Постановка проблеми. Проблема підвищення точності результатів тестування є однією з головних у педагогічній теорії вимірювання. Саме завдання у тестовій формі є тим матеріалом, з якого будується педагогічний тест. Без якісних завдань не можливо створити якісний тест і отримати якісні тестові результати. Остаточним критерієм якості завдань тесту є точність тестових результатів, але потрібні такі наочні показники якості завдань, які можна застосовувати на етапі розробки форми завдання, його попередньої апробації. Одним із таких показників є час виконання завдань тесту. Відомо, що чим менше часу потрібно тестованому для виконання кожного завдання тесту, тим більше завдань йому можна запропонувати за відведений планом навчання час, і тим точніше буде результат вимірювання навчальних досягнень за допомогою тесту. Але зв'язок між часом виконання завдання 
та іншими показниками якості $є$ досить складним і часто не враховується у практичній діяльності з розробки завдань у тестовій формі.

Аналіз останніх досліджень. У класичній теорії тестування якість тестових завдань визначається показниками трудності (частка правильних відповідей на певне завдання в цільовій групі) та роздільної здатності (різниця між частками правильно виконаних завдань у групах тестованих з більшими і меншими тестовими балами). Зручним виявляється застосування коефіцієнта кореляції Пірсона між оцінкою за завдання та загальним тестовим балом. Якщо розподіл тестових балів відповідає нормальному розподілу, застосовують точково-бисеріальний коефіцієнт кореляції, який містить певні поправки до коефіцієнта кореляції Пірсона. Модель Г. Раша [1] дає новий підхід до визначення якості тестового завдання через параметри апроксимуючої функції для залежності ймовірності правильного виконання завдання від підготовленості тестованого — виявляється можливим аналізувати окремо для різної підготовленості тестованих здатність тестового завдання їх розрізняти. Важливим фактором якості тестових завдань виявляється час, який потрібен тестованому для виконання завдання, оскільки загальний час роботи тестованого над тестом обмежений, але надійність результатів тестування збільшується із збільшенням кількості завдань тесту.

Підвищення якості тестових завдань досягається застосуванням правильних форм завдань з лаконічними формулюваннями, відповідністю форми завдання змісту, ретельним редагуванням тексту завдання та дистракторів. Питанням побудови завдань у тестовій формі присвячено багато наукових праць відомих дослідників,

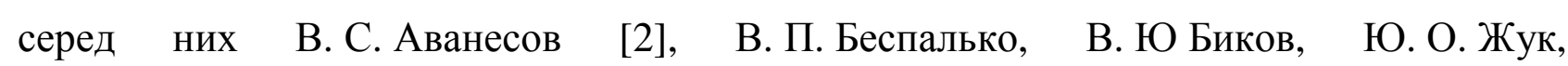
Ю. М. Богачков, І. С. Булах, М. Р. Мруга, Є. В. Медреш, Н. М. Розенберг.

Виділення невирішених питань. Рішення про якість тієї чи іншої версії тестового завдання приймається на підставі експертних оцінок і багатьох емпіричних показників: роздільна здатність, ймовірність угадування, трудність, час виконання. Проте бракує практичних рекомендацій щодо комплексного врахування цих факторів 3 метою формування ефективного педагогічного тесту.

Метою даної роботи є побудова критерію якості тестового завдання 3 урахуванням показників його роздільної здатності та часу виконання. 
Виклад основного матеріалу. Будь-який аналіз якості тестового завдання має спиратися на критерій якості тесту, складовою якого $є$ завдання. Класичним показником якості тестових результатів є коефіцієнт надійності, що визначається як відношення дисперсії істинних значень вимірюваної ознаки до дисперсії результатів вимірювання: $R=s_{y \infty}^{2} / s_{y}^{2}$ [2]. Якщо припустити, що розподіл тестових балів $\epsilon$ нормальним і величина похибки є випадковою й статистично незалежною від значень вимірюваної ознаки, то можна визначити надійний інтервал для отриманого тестового бала від $(y-\Delta y)$ до $(y+\Delta y)$, де $\Delta y=t s_{E}=t s_{y} \sqrt{1-R}$ [2], множник $t$ визначається 3

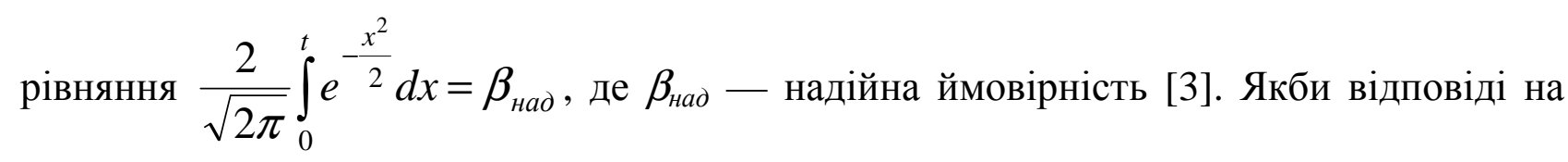
окремі завдання тесту були статистично незалежні, то для випадку обчислення тестового бала як частки правильно виконаних завдань залежність величини похибки від кількості завдань мала б вигляд $\Delta y \sim 1 / \sqrt{m}$. У граничному випадку повної кореляції всіх завдань тесту похибка не залежить від кількості завдань. Припущення, прийняті в класичної теорії надійності тестових результатів, ускладнюють аналіз зв’язку між емпіричними параметрами завдання точністю вимірювання тесту для тестованих $з$ різною підготовленістю (з різним істинним значенням вимірюваної ознаки). Тому критерій якості тестових результатів пропонуємо будувати на підгрунті аналізу правильності ранжування тестованих. Такий критерій не залежатиме від закону розподілу тестових балів та інших припущень.

Пропонуємо здійснювати аналіз на підставі методу статистичних випробувань. Нехай для двох тестованих заздалегідь відомо, що один з них підготовлений краще (звісно потрібна певна міра підготовленості, ця міра може бути визначеною за будьякою однією шкалою). За результатами тестування після застосування певної процедури інтерпретації даних можливі три ситуації:

- правильне ранжування тестованих;

- не виявилено різниці в підготовці тестованих;

- помилка в ранжуванні тестованих.

Оскільки тестові результати містять випадкові похибки, розглянуті вище ситуації виникатимуть випадково. На підставі великої кількості випробувань можливо побудувати розподіл імовірностей розглянутих ситуацій. Звісно, чим більше 
різниця у підготовленості випробуваних, тим вище ймовірність правильного їх ранжування за певною процедурою інтерпретації тестових балів. Критерієм якості тестових результатів $(Q)$ оберемо різницю між імовірністю правильного та неправильного висновку щодо ранжування тестованих. Саме такий критерій, на наш погляд, є найбільш наочним і зручним. Він змінюється від нуля, коли процедура не забезпечує диференціацію тестованих, тобто кількість правильних і неправильних висновків однакова, до одиниці, коли всі висновки правильні.

Організувати лабораторні випробування 3 великою кількістю тестованих неможливо, тому потрібно розробити модель тестованого й процедур тестування та інтерпретації тестових результатів. Для цього потрібні певні припущення. Нехай імовірність правильного виконання завдання тесту добре апроксимується трипараметричною моделлю Г. Раша [1]. Таке припущення природне, оскільки відомі емпіричні дані (наприклад, експериментальні дослідження В.Ю.Бикова, Ю. М. Богачкова, Ю. О. Жука [4, с. 122-123], наші результати [5] та ін.) свідчать про адекватність моделі Г. Раша. Припустимо, також, що параметри кожного завдання не залежать від особистості тестованого. Таке припущення можливо, якщо тест гомогенний, тобто всі завдання перевіряють один елемент навчального матеріалу, що виключає вплив прогалин у структурі навчальних досягнень тестованого. Отже, в основу моделі тестових результатів пропонуємо покласти ймовірність надання правильної відповіді як функцію від параметрів завдання у вигляді:

$$
p=\frac{1}{1+\exp (-a \cdot(\theta-b))},
$$

де $\theta$ - підготовленість тестованого, виражена в логітах; $a-$ параметр завдання, що характеризує його роздільну здатність; $b-$ показник трудності завдання.

Розглянемо процедуру статистичних випробувань. Вхідними даними $є$ підготовленість кожного 3 випробуваних $\theta_{1}, \theta_{2}\left(\theta_{2}>\theta_{1}\right)$ та параметри кожного завдання тесту. Формуємо вектори відповідей першого й другого тестованого. Випадково, з імовірністю, що обчислюється за формулою (1), назначаємо відповіді правильними або неправильними. Обчислюємо тестовий бал. Якщо за тестовим балом випробуваний 3 підготовленістю $\theta_{2}$ виявляється кращим, то висновок інтерпретації правильний, інакше різниця не виявлена або визначається помилка в 
ранжуванні. Багаторазово повторюємо випадкове формування вектора відповідей i обчислення тестового бала. В обчислювальних експериментах кількість статистичних випробувань складала 100000, що за наближеними оцінками з імовірністю не менше $95 \%$ забезпечувало дві правильні цифри у шуканому значенні критерію $Q$.

На рис. 1 і 2 подано результати дослідження якості інтерпретації тестових результатів за класичною процедурою, коли тестовий бал визначається як кількість правильно виконаних завдань. За віссю абсцис відкладено різницю між підготовленістю двох тестованих $\left(\theta_{2}-\theta_{1}\right)$ в логітах. Ряди даних відображають значення критерію $Q$ як функції від $\left(\theta_{2}-\theta_{1}\right)$ для різної середньої підготовленості цих тестованих $\theta=\left(\theta_{2}+\theta_{1}\right) / 2$.

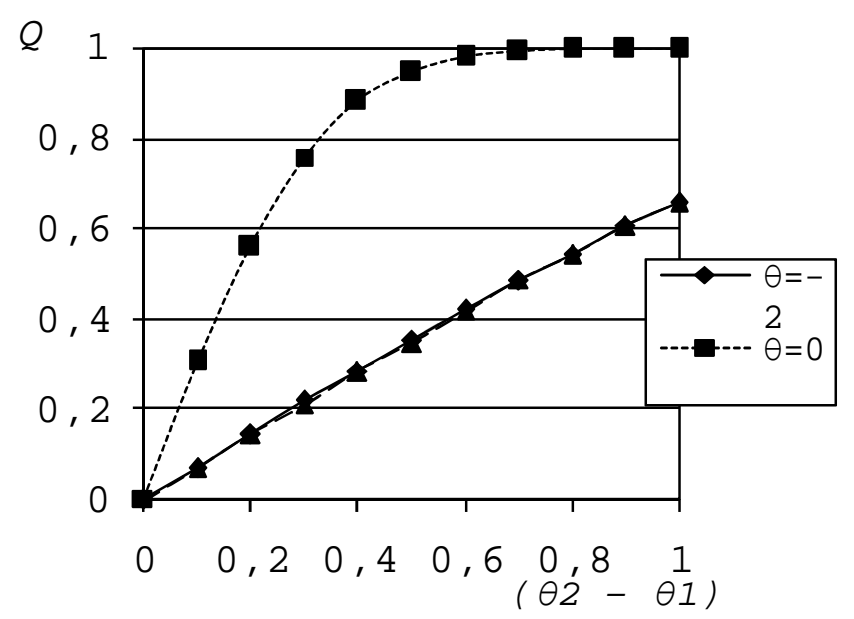

Рис. 1. Критерій $Q$ якості ранжування тестованих за класичної процедурою обчислення тестового бала для тесту, який складається з 31 завдання однакової трудності з параметрами $b=0, a=2$.

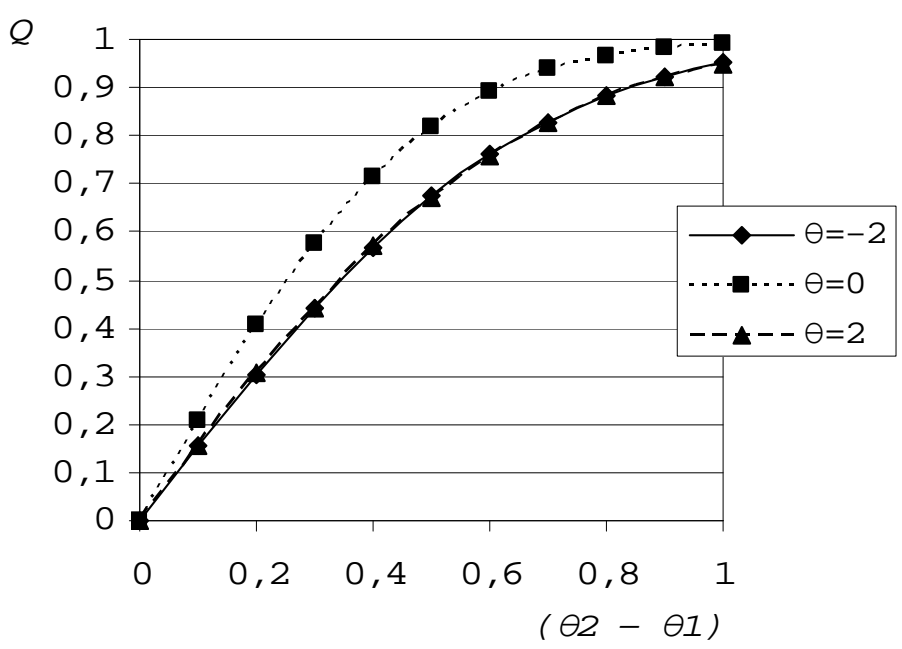

Рис. 2. Критерій $Q$ якості ранжування тестованих за класичної процедурою обчислення тестового бала для тесту, який складається з 31 завдання зростаючої трудності (від $b=-2$ до $b=2$ ), з параметрами $a=2$. 
Результати обчислювальних експериментів збігаються з відомими висновками, що класична процедура інтерпретації тестових результатів забезпечує найкраще розділення тестованих, коли їх підготовленість близька до трудності завдань тесту (рис. 1 , ряд даних $\theta=0$ ). Для цього випадку проведемо обчислювальні експерименти для визначення впливу роздільної здатності завдання (рис. 3) і кількості завдань тесту (рис. 4)

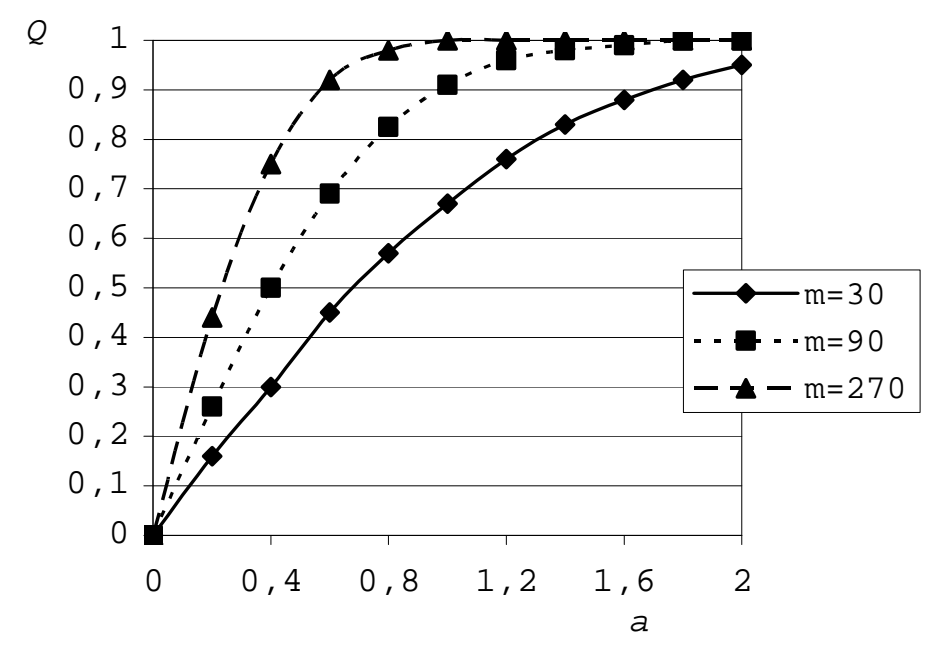

Рис. 3. Вилив показника роздільної здатності завдання на якість інтерпретаиії тестових результатів: критерій $Q$ обчислено для випадку ранжування тестованих з різнищею підготовленості $\left(\theta_{2}-\theta_{1}\right)=0,5$ i середньою підготовленістю $\theta=\left(\theta_{2}+\right.$ $\left.\theta_{1}\right) / 2=0$ для тесту, який складається $3 \mathrm{~m}$ завдань однакової трудності 3 параметрами $b=0$.

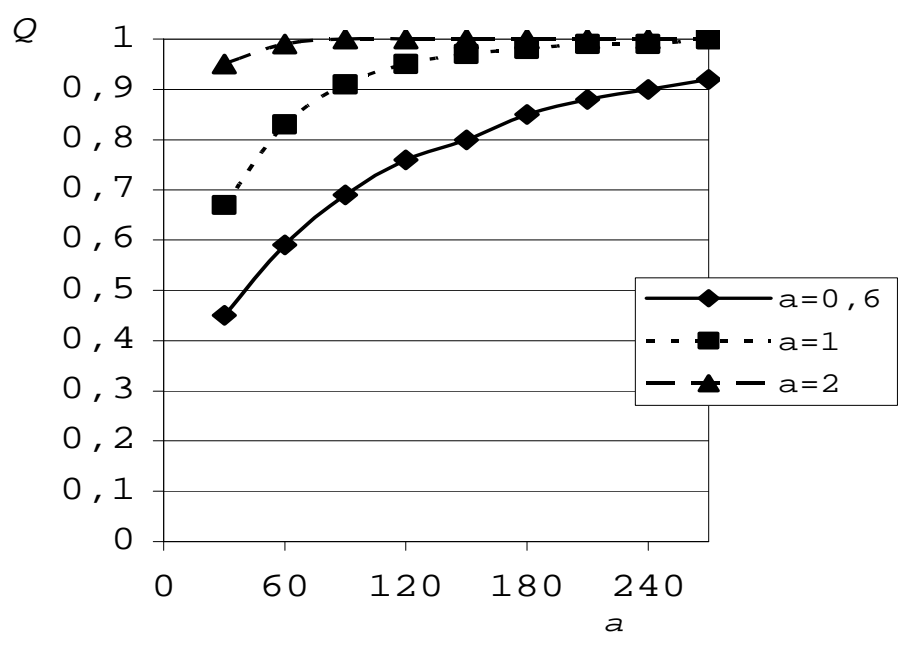

Рис. 4. Вплив кількості завдань тесту на якість інтерпретаиії тестових результатів: критерій $Q$ обчислено для випадку ранжування тестованих з різницею підготовленості $\left(\theta_{2}-\theta_{1}\right)=0,5$ і середньою підготовленістю $\theta=\left(\theta_{2}+\theta_{1}\right) / 2=0$ для тесту, який складається із завдань однакової трудності $(b=0)$ з параметрами $a=0,6 ; a=1 ; a=2$. 
Аналіз результатів обчислювальних експериментів (рис. 3 і рис. 4) дає змогу дістатися висновку, що залежність обраного критерію $Q$ від параметра $a$ та кількості завдань тесту добре наближає функція (максимальна абсолютна похибка 0,02):

$$
\frac{\exp (0,3 a \sqrt{m)}-1}{\exp (0,3 a \sqrt{m)}+1}
$$

у якій можна виокремити комплекс $a \sqrt{m)}$ як критерій якості тестових результатів.

Цей результат обчислювального експерименту відповідає теоретичної оцінці стандартного відхилення тестового балу в моделі IRT [1, с. 90]:

$$
S E(\theta)=\frac{1}{\sqrt{\sum_{j=1}^{m} a_{j}^{2} P_{j}(\theta)\left(1-P_{j}(\theta)\right)}},
$$

де $P_{j}(\theta)$ - імовірність правильного виконання тестового завдання випробуваним 3 підготовленістю $\theta$. У випадку однакової роздільної здатності й трудності всіх завдань тесту маємо:

$$
S E(\theta)=\frac{1}{P(\theta)(1-P(\theta)) a \sqrt{m}}
$$

У реальному навчальному процесі загальний час тестування фіксований, тому кількість завдань тесту обернено пропорційна часу виконання кожного із завдань, таким чином, зручним критерієм якості завдання виявляється комплекс:

$$
\frac{a}{\sqrt{t}}
$$

де $t$ - час виконання завдання.

Означений вище результат отримано для випадку, коли всі завдання тесту мають однакову роздільну здатність і трудність, яка забезпечує правильне виконання завдання тестованим з імовірністю 1/2. Але такий тест має вузький робочий діапазон вимірювання і для тестованих з низькою або високою підготовленістю не забезпечує задовільної якості вимірювання (рис. 1 ряди даних $\theta=-2$ і $\theta=2$ ). Сучасні педагогічні тести будуються як система завдань зростаючої трудності, що дозволяє суттєво розширити робочий діапазон вимірювання (рис. 2), але чутливість тесту, тобто його здатність розділяти тестованих 3 невеликою різницею підготовленості зменшується. Заміна числового коефіцієнта емпіричної формули 2 на значення 0,24 забезпечує 
задовільне наближення результатів обчислювальних експериментів для такого тесту (рис. 2). Але абсолютна похибка наближення стає більшою (до 0,06). Таким чином, запропонований комплекс $\frac{a}{\sqrt{t}}$ може застосовуватися для попереднього аналізу якості завдань реального педагогічного тесту, але для точного визначення впливу кожного завдання на якість тестових результатів слід користуватися більш точними методами, наприклад, розробленою нами моделлю для проведення статистичних випробувань.

\section{Висновки.}

1. Запропоновано універсальний критерій якості тестових результатів $(Q)$ як різниця між імовірністю правильного і неправильного висновку щодо ранжування тестованих.

2. Запропоновано метод визначення критерію $Q$ на основі статистичних випробувань.

3. Обчислювальний експеримент підтверджує відомий висновок, що найбільша якість ранжування тестованих забезпечується, якщо тест містить завдання однакової трудності, яка близька до підготовленості тестованих. Але такий тест має вузький діапазон вимірювання.

4. Показано вплив часу виконання завдання на якість тестових результатів. Запропоновано застосовувати комплекс $\frac{a}{\sqrt{t}}$ як критерій якості тестового завдання і показано його обгрунтованість.

Перспективи подальших розвідок 3 проблеми дослідження: доцільно дослідити зв'язок між часом виконання тестового завдання, трудністю завдання i ймовірністю угадування правильної відповіді 3 точки зору їх впливу на якість тестових результатів.

\section{Список використаних джерел}

1. Baker F. B. The Basics of Item Response Theory / F. B. Baker. - USA : ERIC Clearinghouse on Assessment and Evaluation, 2001. - 176 p.

2. Аванесов В. С. Форма тестовых заданий / В. С. Аванесов. - М. : Центр тестирования, 2005. - 156 с. 
3. Жалдак M. I. Теорія ймовірностей і математична статистика $з$ елементами інформаційної технології / М. І. Жалдак, М.Н.Кузьміна, С. Ю. Берлінська. - К. : Вища шк., 1995. - 351 с.

4. Моніторинг рівня навчальних досягнень 3 використанням Інтернеттехнологій [Текст] / В. Ю. Биков, Ю. М. Богачков, Ю. О.Жук ; [за ред. : В. Ю. Биков]. — К. : Педагогічна думка, 2008. - 127 с.

5. Білоусова Л. І. Методика обробки та інтерпретації результатів педагогічної діагностики / Л. І. Білоусова, О. Г. Колгатін // Комп’ютер у школі та сім’ї. — 2003. № 8. - C. 28-31.

\section{ДЛИТЕЛЬНОСТЬ ВЫПОЛНЕНИЯ КАК ОДИН ИЗ ПОКАЗАТЕЛЕЙ КАЧЕСТВА ТЕСТОВЫХ ЗАДАНИЙ}

Колгатин Александр Геннадиевич, доктор педагогических наук, профессор кафедры информатики Харьковского национального педагогического университета шимени Г. С. Сковороды, г. Харьков, e-mail: kolgatin@yahoo.com

\section{Аннотация}

Проблема влияния характеристик тестовых заданий на точность результатов педагогического тестирования исследуется с помощью разработанной автором методики проведения вычислительных экспериментов, которая основана на методе статистических испытаний и модели Г. Раша. Предложено критерий качества результатов тестирования как разность вероятностей правильного и ошибочного ранжирования тестируемых. По результатам вычислительных экспериментов исследовано зависимость этого критерия от параметра разделяющей способности и количества заданий теста. Предложено эмпирическую функцию для аппроксимации полученных данных, на основе анализа которой рекомендовано критерий качества задания, учитывающий показатели длительности выполнения и дифференцирующей способности.

Ключевые слова: тест, длительность, параметр дифференцирующая способность, вычислительный эксперимент, точность. 


\section{EXECUTION TIME AS A FACTOR OF THE TEST TASK QUALITY}

Olexandr H. Kolgatin, Dr. of Pedagogical Sciences, professor of the informatics chair, Kharkiv National Padagogical University named after G.S.Skovoroda, Kharkiv, e-mail: kolgatin@ukr.net

\section{Resume}

Influence of the test tasks characteristics on the test results quality is researched with author's method of computational experiments. This method is based on statistical tests and G. Rasch model. Criterion of the test results quality as the difference of probabilities of correct and incorrect ranking of the examinees is proposed. The dependence of this criterion on the discrimination parameter and the number of test items is studied according to the results of numerical experiments. The empirical function for the approximation of this data is suggested and used to propose the quality criterion that takes into account the duration of the item execution and the discrimination parameter of this item.

Keywords: test, execution time, discrimination, computational experiment, accuracy. 